\title{
OSCAR HERMES VILLORDO: RUPTURAS EN EL CANON LITERARIO
}

\section{OSCAR HERMES: RUPTURAS NO CÂNONE LITERÁRIO}

\author{
Aldo Oscar Valesini"
}

Resumo: O romance La brasa en la mano, de Oscar Hermes Villordo produz uma quebra no cânone vigente na literatura argentina a partir da intervenção da Ditadura Militar. Os valores morais, religiosos e estéticos permitidos observavam um dispositivo estabelecido que diferenciava o permitido do proibido. O texto, gestado, durante este período publica-se no ano do advento da democracia e expõe, de maneira exponencial, a presença do subalterno como categoría discursiva genuína. Tanto o conteúdo como a linguagem expõe um mundo marginal e negado no espaço sócio-político dominante. Cremos que a obra é parte do campo cultural da ditadura, a que menciona indiretamente através de seu oposto.

Palabras Clave: Oscar Hermes Villordo; La brasa en la mano; literatura gay en Argentina.

AвSTRACT: The romance La brasa en la manoby Oscar Hermes Villordo breaks the Argentinian literature canon from the intervention of Military Dictatorship. The moral, religious and aesthetic values allowed at the time were in accordance to a device established that differentiated between the allowded and the prohibited. The text, written at that period is published inthe year of the advent of democracy and exposes the presence of the subordinate as a genuine discursive category. Both content and language expose a marginal world that is denied in the dominant sociopolitical space. It is believed that the work is an important element of the cultural dictatorship field that is indirectly mentioned through its opposite.

KeYwords: Oscar Hermes Villordo; La brasa en la mano; gay literatura in Argentina.

"Aldo Oscar Valesini doctor en literatura, Universidad Nacional del Nordeste. E-mail: aldovalesini@gmail.com 
La literatura gay en Argentina no ha sido una excepción especialmente en el corpus de las literaturas hispanoamericanas en cuanto a conformar un desborde de un sistema literario homogéneo en relación con los imperativos burgueses llegados de Europa. Según la crítica, la temática se inicia con la mención en episodios aislados que tienen como antecedente principal la recordada escena de El Matadero, de Esteban Echeverría, en la que se somete al unitario. Todos los casos corresponden a situaciones que reproducen simbólicamente en el discurso el espacio que le estaba asignado en la sociedad: episodios cuyo valor es mínimo, resignándose a la periferia semántica, como catálisis o elementos periféricos al tema que por lo tanto difícilmente pueden adquirir significado autónomo. La Brasa en la mano, novela del escritor chaqueño Oscar Hermes Villordo constituye un quiebre en esa constante. Tanto discursiva como temáticamente está ordenada en torno del tema de la homosexualidad, lo cual significa una ruptura con el canon conservador de la literatura argentina fijado a fines del siglo XVIII por las ortodoxias borbónicas.

La publicación, entonces, adquiere un valor semiótico como acontecimiento concordante con la caída irreversible de la Dictadura Militar argentina. El contexto se incorpora al enunciado y adquiere un sentido ambivalente en las relaciones entre el concepto de lo público y lo privado a través de los registros del lenguaje. La sustancia narrativa -discursiva- de la obra se arraiga a la manera de bisagra en el cronotopo de su producción.
Sostenemos que la presencia del discurso se apropia de la historia al punto que, a la manera proustiana, la sustancia novelesca se reduce al nivel de la conciencia, al registro detallado de los acontecimientos trivialesdelavida cotidianadelos personajes, lo cual implica una suerte de negación de su entidad como sujetos históricos, entendidos según los presupuestos del disciplinamiento militar a partir de jerarquías y regulaciones patriarcales.

En ese contexto, nos interesa abordar las relaciones de la obra con el contexto histórico, tanto en relación con el sistema social gestado en la transición democrática como el que se produce en relación diacrónica en el sistema literario.

La obra, instalada como un ícono resignificado por su marginalidad adquiere un valor paradójicamente positivo, cual es el de ampliar el horizonte del discurso, explorar lingüísticamente los bordes que la cultura se había esforzado en excluir a través de la innominación.

En una sociedad caracterizada por la persecución al diferente, de exclusión del peligroso, de supresión del otro entendido como una identidad autónoma y crítica, el autor instala un mundo semióticamente transgresor, instalado al margen de los imperativos políticos. La literatura, entonces, se constituye en mundo, un mundo que visibiliza las zonas marginales del cuerpo social pero que forman parte de un mismo entramado humano, burocrático, espacial. Esa sociedad, obediente irremediablemente a las directrices verticales del poder, encuentra aquí un 
código subalterno, una forma de expandir la conciencia y reconocer que el discurso es capaz de transgredir los bordes y situarse en el lugar del otro.

El otro representado en el gay, aunque el sema es intercambiable con el negro, el originario, el discapacitado. En este sentido hay una muestra de tolerancia y una proposición de resignificar al hombre como una entidad que adquiere un lugar equivalente a su presencia antes que a su adhesión a una forma de pensamiento. La condición humana está dicha a partir del diálogo antes que el monólogo, de la construcción horizontal antes que la jerarquía que ordena y suprime.

\section{UNA OBRA INAUGURAL}

La novela de Oscar Hermes Villordo, se publicó en 1983 y constituye, junto a La otra mejilla (1986) y El ahijado (1990) una trilogía de la visibilidad homoerótica a través de la presentación de la vida y las costumbres de personajes varones homosexuales porteños, ubicados cronológicamente entre los años 1950 y 1960 . El autor, chaqueño de origen, se radicó prontamente en Buenos Aires, donde desarrolló una tarea literaria reconocida a nivel nacional, miembro y colaborador de distintas instituciones culturales y además trabajó en los principales diarios del país. El hombre incorporado al devenir de la cultura de la gran ciudad, produce con esta producción narrativa un quiebre en su discurso.

La publicación de la novela constituye un antecedente de relevancia en la historia literaria, pero especialmente en la conformación de los itinerarios discursivos en la Argentina a través del registro de una zona de exclusión y anomia. Hasta entonces, desde Esteban Echeverría, nunca la cuestión se había impuesto como el tema central sobre el que se articularían los distintos acontecimientos del relato. La categoría del sema "homosexualidad" no se circunscribe a una secuencia específica entre otras de la historia, sino que adquiere cualitativamente el carácter de tópico macroestructural, la construcción semiótica de primer grado sobre la cual se disponen los acontecimientos encarnados por los personajes, casi todos relacionados solidariamente con el tópico.

Lanovela, porotraparte, habladelavida, aquella que circula más allá de la literatura; su dimensión semántica concuerda con escenas del imaginario colectivo sobre el que pesa la censura moral y política pero que sin embargo no resultan extraños. No son ajenos en primer lugar a todos los integrantes de la comunidad homosexual, pero tampoco a la sociedad en general que convive con distintas reacciones frente a estas manifestaciones que introducen escenas de tensión y requieren una revisión respecto de un paradigma conformado por la tradición y por la legislación.

La obra reformula la representación del concepto de vida cotidiana a partir de la presentación de un sector social constituido por los homosexuales -sus códigos, su lenguaje, sus hábitos-. Los acontecimientos corresponden al ámbito equivalente al espacio no-público: ambientes interiores, calles nocturnas, mingitorios, rincones 
desiertos, todo aquello que está privado de la mirada del tercero. Son otros los sentidos que predominan: el olfato, el tacto, la audición. El denominador común de estos territorios consiste en su pertenencia a la periferia: las acciones prohibidas, los espacios oscuros, personas improductivas, actividades banales que tienden a la autosatisfacción. Este ámbito se constituye en un discurrir yuxtapuesto al de la organización de la vida pública, donde las atribuciones de "convencional" y "normal" se constituyen en sinónimos acotados por las pautas dominantes.

La organización del espacio público y del espacio privado responde a regulaciones de tipo estructural en la sociedad -la religión, el orden policial, la moral, la tradiciónque adquieren en este texto una doble relevancia. Por un lado, estética, en la medida que legitima en el discurso un ámbito perteneciente a la vida privada. El arte entonces se acomoda a las estrategias de subversión de las vanguardias, aunque el carácter experimental no abarca el orden formal del discurso. Por otro, la inversión de los espacios representa una respuesta a la hegemonía represiva de la dictadura, centrada en las formas visibles de concordancia entre un sistema de regulaciones y las prácticas permitidas. Los dispositivos enunciativos de la Dictadura se ocuparon minuciosamente en la organización de una imagen uniforme basada en el orden, la disciplina, la regularidad como dispositivo de ocultamiento de la contracara necesaria para la imposición de aquel orden: la persecución, la violación y la muerte.
Al mismo tiempo, la novela da cuenta de un esquema de relaciones socioeconómico-afectivas que expone un nuevo contorno de la periferia. Al margen de la economía de mercado, de los conceptos de producción y de crecimiento individual y social, este sector reduce sus expectativas al intercambio casual de sexo que se constituye en un complemento a la exaltación de la dimensión subjetiva del sujeto, concebida como el horizonte existencial planteado en términos pragmáticos antes que metafísicos. Hay, entonces, una asimilación al concepto se individuo improductivo como sujeto de un campo social El discurso despliega las modalidades del ser en su carácter relacional cancelado del interés comunitario unido al progreso. Más allá de que la naturaleza de las relaciones impone su reducción al ámbito exterior de la visibilidad legal o moral, el proyecto sobre el que se organiza la inserción de los individuos en el dispositivo económico los torna en no-sujetos, en seres invisibles en los términos de la economía de mercado, más próximos a las reglas de las tribus o los feudos medievales en que la convivencia se reduce a la satisfacción de los intereses personales, acotados en el espacio y el tiempo.

\section{Dictadura E Discurso}

El Proceso de Reorganización Nacional (1976-1983) significó la reordenación de principios de convivencia de la sociedad argentina en un todo de acuerdo con las manifestaciones culturales e ideológicas de un grupo de "militares iluminados" 
imbuidos de mesianismo autoritario. Entendieron que los vicios del mundo político debían ser aniquilados para restituir valores propios de dictaduras anteriores creando un país nuevo donde las prácticas sociales debían uniformarse. El respeto a valores como Patria, Familia y Tradición representaban estos conceptos. .

Todo lo que excediera estos preceptos se consideraría atentatorio contra los valores nacionales, contra la familia y la moral. Es así como los obreros y los sindicalistas que se oponían al modelo económico de la escuela de Chicago (defendida por sectores de la oligarquía argentina) debían ser disciplinados. Violencia represiva $\mathrm{y}$ liberalismo económico signarían esos oscuros años de la dictadura

A ellos se unirían inmediatamente todos los grupos subordinados para ser uniformemente incluidos en este esquema de poder "garante del orden". Así hasta la vestimenta tanto masculina como femenina era controlada, el aspecto personal y las manifestaciones de afecto en los lugares públicos, los vínculos sociales, etc. Según este aparato represivo era impensable que los homosexuales tuvieran un espacio de manifestación en cualquiera de sus formas y el esquema de representación patriarcal era el único posible La persecución del diferente no estaba circunscripta solamente al plano ideológico (marxismo, comunismo, montoneros, etc.) sino también a todas las otras formas de la organización o prácticas individuales o colectivas de carácter público que pudieran, a su criterio, resultar peligrosas. No obstante Tales manifestaciones pueden ocultar un miedo latente en ellos. Las imágenes del "hombre" biológicamente superior, la consolidación de la fuerza bruta y la marginación de lo diferente eran el espejo en que se miraban.

El número de muertos y desaparecidos homosexuales no es mayormente significativo en relación con otros grupos, en parte por la invisibilidad de sus prácticas (en la novela se expone la delgada línea que separa la adecuación a lo normal y la vida sexual disimulada), y en otra, por un residuo homoerótico que sin dudas está presente en la exaltación de los valores masculinos como prototipo.

El concepto de orden, tanto en lo político como en lo social se constituyó en una categoría de valor que sostenía el universo de lo representativo. El orden legitima una jerarquía: el hombre en la familia, el jefe en las organizaciones sociales, los preceptos (morales, religiosos, legales) como principio de orden inalterable.

En ese campo cultural signado por la mirada vigilante, el lenguaje contenido, la amenaza permanente, las formas del pensar $-y$ consecuentemente de escribirse remitían a la reproducción inocua de modelos, historias, prototipos admitidos en función de su presunta función didácticomoralizante. La novela no introduce un cambio profundo en el orden impuesto en la dictadura; solamente se corre de manera sesgada el límite entre el universo secreto de los gays que se entremezcla con el quehacer rutinario de la ciudad. El Proceso está presente en el discurso, como una huella que, sin ser mencionada produce vacíos, estimula desbordes, asegura un margen de libertad de género como un derecho humano 
básico. El macrosistema de líneas de fuerza impuesto sobre la sociedad es el que articula la desviación, el tono disonante que indaga otros sistemas, cuyas coordenadas vitales fundan un orden diferente.

\section{LA BRASA EN LA MANO}

La historia de la novela se ordena a partir de una trama sostenida en una secuencia de acontecimientos triviales, casi intrascendentes en la vida pública, aunque constitutivos fundante de las subjetividades de los sujetos que aparecen. La sustancia narrativa formula un campo cultural marginal, que contradice las expectativas de funcionamiento discursivo reguladas por la concepción burguesa y autoritaria que regía políticamente la totalidad del conjunto social.

La vida privada - el mundo gay - se reduce al relato de los avatares de personajes que oscilan entre los recorridos individuales o grupales en su pretensión de lograr sexo con encuentros pasajeros y la construcción de las fantasías y representaciones que expanden el tiempo en el discurso.

Beto insistía en su furia contra los militares, pero apenas vio unas botas me arrastró tras ellas. 'Los conscriptos son otra cosa?, me explicó. 'Ellos no tienen la culpa.? Myriam se había quedado atrás, hablando con el heladero. Miré hacia la gran estatua ecuestre rodeada de alegorías y allí vi a Adolfo, inmóvil de perfil, como si él formara parte del grupo escultórico. (p. 46)

Las escenas de travestismo, de confesiones y estrategias para conseguir el favor de un amante casual, los catálogos de "chongos" (nombre que se daba al 'taxi boy') pertenecientes a determinados grupos sociales instalados en la periferia: albañiles, conscriptos, empleados, registra una complejidad mayor en el panorama de la sexualidad que públicamente aparece registrada y afirmada en la taxonomía varón / mujer.

Así como el desarrollo semántico abunda en la formulación del mundo homoerótico, también el lenguaje lo traduce como práctica que atraviesa la separación entre las tipologías discursivas atribuidas convencionalmente al hombre y a la mujer. La novela está relatada en primera persona por Pajarito, un personaje que actúa como hilo conductor de un conjunto de personajes protagonistas de los episodios clave de la vida gay. El lenguaje, entonces, es la irrupción de la conciencia del narrador, la exposición de sus dudas, sus miedos y sus fantasías al punto de constituir una tipología cercana al lenguaje femenino, no solo porque el deseo erótico se orienta hacia la relación con otro hombre, sino porque el vocabulario, la adjetivación, las conexiones causales que lo organizan se asimilan al discurso de la mujer. También la incorporación de los diálogos con los demás personajes conforman un corpus que en la conciencia colectiva se atribuye a la mujer: temática banal, chismes, exclamaciones, etc.

Andrea estaba en la bañadera, una pierna asomada en el costado, el cuerpo hundido en la espuma. Había corrido a abrirnos la puerta y las huellas mojadas de sus pies se 
veían en el piso. Era la hora en que tomaba el baño, de vuelta al trabajo, y la vida comenzaba para ella. Nos hablaba detrás de la cortina, que sólo dejaba ver la pierna. "No me miren", decía, "en cinco minutos salgo". Sus cinco minutos eran algo más de cinco, pero nunca importaba. "En la heladera hay pollo", nos invitó. Pero Beto ya se había adelantado y venía con un enorme muslo para él y un ala arrugada para mí. La certeza me había dado hambre y devoré la presa. "Se ve que era un pollo que marcaba el paso" comentó Beto, aludiendo a la pretendida dureza del pollo pero en verdad hablando del militar” ¡Pero no! ¡Si ya me saqué las botas! Se oyó a Andrea ... (p. 57)

Aunque según Coates (2009) los estereotipos correspondientes al género masculino y femenino han experimentado una tendencia a la disolución en los últimos años, producto de la incidencia que ha tenido la irrupción de grupos (feministas, gays, lésbicas, etc.) que afirman su no pertenencia al esquema binario, en este caso la sustancia del discurso se reduce a la configuración de una acción meramente especulativa, centrada en el dato momentáneo, la futilidady la subordinación a las ocurrencias individuales. El sentido de la acción lingüística se orienta a la sexualidad despojada de connotaciones que impliquen algún tipo de proyección o trascendencia. Tanto la enunciación como el contenido son parte de un instante que se diluye, a pesar de que el protagonista, al final, intenta preguntarse por un futuro que no deja de ser afectivo en todo caso.

\section{ConClusiones}

Las estrategias discursivas del relato se organizan en torno de la vida interior de los personajes y en ese sentido postulan una forma que reproduce formalmente la práctica institucionalizada por la represión. Esa vida interior aparece como marco en la autobiografía, pero también en el contexto de las relaciones -tanto casuales como permanentes- en que el lenguaje agota su referencia en la literalidad del mundo gay. La historia, entonces, aparece ajena al canon establecido como criterio de jerarquía y legitimidad, perteneciente a una subcultura excluida.

La autoconciencia se materializa en la construcción de la subjetividad y en el establecimiento dellogos en dos direcciones: endógena, hacia el reconocimiento de los iguales -la comunidad de amigos-, y exógena, en relación con los vínculos con los hombres que acuden o acceden a la petición sexual. Más lejos la sociedad se conforma como un escenario neutralizado en la mirada de los sujetos de la historia.

De ese modo se visualiza la conformación compleja de las categorías de género en la sociedad. Aparece el subgrupo: aquellos que se definen como heterosexuales, aunque la misma relación con los homosexuales los convierte, si no en homosexuales, en bisexuales, a pesar de las razonesque pudieranjustificar sus prácticas. El mismo conglomerado gay aparece con modalidades, diferencias que exceden las peculiaridades individuales.

La obra se instala en el espacio obturado por la dictadura: aquel constituido por la 
palabra en el escenario privado. La dictadura se presenta como una huella en el sentido derridiano: la ausencia que ofrece un lugar, el espacio vacío que de pronto es ocupado en el relato por los homosexuales que afirman lo mismo que eran antes, aunque ahora legitimado por el discurso público. La huella contiene el desplazamiento de lo secreto al ámbito de la comunicabilidad sin trabas. En la obra comparecen, al tiempo que la literal descripción de la vida de los grupos de homosexuales de buenos Aires, las nociones patriarcales que la tradición cristiana y la ortodoxia militar afirmaron como espacio privilegiado de la sociedad. Los personajes homosexuales afirman el concepto patriarcal que asigna un papel determinado al género masculino y otro al género femenino. No alcanzan a constituir efectivamente una construcción ideológica -a través de su discurso y de su estancia social- de un nuevo paradigma que amplíe efectivamente el binarismo de género.

El campo cultural (P.Bourdieu) conformado en el texto a través de los personajes integrados en un espacio definido es una red compleja de relaciones abiertas en diálogo con otros campos: la moda, la publicidad, la estética, los entretenimientos. El denominador básico de la conformación marginal se sitúa en relación con la restitución discursiva de la subjetividad homoerótica. Sin embargo, no deja de ser una construcción sesgada que suprime la dimensión constitutiva del sujeto como ser integrante de un colectivo mayor de orden social y jurídico, regido por las condiciones del mercado: generador de bienes, ejecutor de funciones delimitadas a partir de normas sustentadas en el sexo antes que en el género.

La sanción moral desaparece en la formación discursiva (Foucault) de los personajes a través de la superación de la dialéctica entre la normalización y la excepción. La adopción de la perspectiva del narrador protagonista ofrece la legitimación de otra normalidad, de otro discurso, de otro modo de estar en el mundo que procede a partir de un sistema cuyas pautas de funcionamiento operan a partir de un proyecto de vida que se agota en la sexualidad.

\section{REFERENCIAS}

BOURDIEU, P. Campo de poder, campo intelectual, Buenos Aires, Cuadratta, 2003 COATES, J. Mujeres, hombres y lenguaje, México, Fondo de Cultura Económica, 2009

MILLET, K. Política sexual, Valencia, Cátedra, 1970

ROUQUIÉ, A. A la sombra de las Dictaduras. La democracia en América Latin, "Buenos Aires, Fondo de Cultura Económica, 2011

SARROCCHI CARREÑO, A. Erotismo y homosexualismo en la narrativa chilena contemporánea, Valparaíso, Ediciones Liceo Técnico Femenino, 2008

VILLORDO, O. H. La brasa en la mano, Resistencia, Librería de la Paz, 2010

Recebido para publicação em 11 de jun. de 2014. Aceito para publicação em 06 de ago. 2014. 